\title{
Within- and Between-Individual Variation in Energy and Nutrient Intake in Japanese Adults: Effect of Age and Sex Differences on Group Size and Number of Records Required for Adequate Dietary Assessment
}

\author{
Azusa Fukumoto ${ }^{1}$, Keiko Asakura², Kentaro Murakami ${ }^{3}$, Satoshi Sasaki ${ }^{3}$, Hitomi Okubo ${ }^{1}$, Naoko Hirota ${ }^{4}$,
} Akiko Notsu ${ }^{5}$, Hidemi Todoriki ${ }^{6}$, Ayako Miura $^{7}$, Mitsuru Fukui ${ }^{8}$, and Chigusa Date ${ }^{9}$

${ }^{1}$ Department of Social and Preventive Epidemiology, Graduate School of Medicine, the University of Tokyo, Tokyo, Japan

${ }^{2}$ Department of Preventive Medicine and Public Health, Keio University School of Medicine, Tokyo, Japan

${ }^{3}$ Department of Social and Preventive Epidemiology, School of Public Health, the University of Tokyo, Tokyo, Japan

${ }^{4}$ Department of Health and Nutritional Science, Faculty of Human Health Science, Matsumoto University, Matsumoto, Nagano, Japan

${ }^{5}$ Department of Food Science and Nutrition, Tottori College, Tottori, Japan

${ }^{6}$ Department of Public Health and Hygiene, School of Medicine, University of the Ryukyus, Nakagami-gun, Okinawa, Japan

${ }^{7}$ Department of Health and Nutritional Science, Faculty of Health Promotional Science, Hamamatsu University, Hamamatsu, Shizuoka, Japan

${ }^{8}$ Department of Statistics, Osaka City University Medical School, Osaka, Japan

${ }^{9}$ Department of Food Science and Nutrition, School of Human Science and Environment, University of Hyogo, Himeji, Hyogo, Japan

Received May 28, 2012; accepted November 13, 2012; released online April 13, 2013

Copyright (C) 2013 Japan Epidemiological Association. This is an open access article distributed under the terms of Creative Commons Attribution License, which permits unrestricted use, distribution, and reproduction in any medium, provided the original author and source are credited.

\begin{abstract}
Background: Information on within- and between-individual variation in energy and nutrient intake is critical for precisely estimating usual dietary intake; however, data from Japanese populations are limited.

Methods: We used dietary records to examine within- and between-individual variation by age and sex in the intake of energy and 31 selected nutrients among Japanese adults. We also calculated the group size required to estimate mean intake for a group and number of days required both to rank individuals within a group and to assess an individual's usual intake, all with appropriate arbitrary precision. A group of Japanese women (younger: 30-49 years, $n=58$; older: 50-69 years, $n=63$ ) and men (younger: 30-49 years, $n=54$; older: 50-76 years, $n=67$ ) completed dietary records for 4 nonconsecutive days in each season (16 days in total).

Results: Coefficients of within-individual variation and between-individual variation were generally larger in the younger group than in the older group and in men as compared with women. The group size required to estimate a group's mean intake, and number of days required to assess an individual's usual intake, were generally larger for the younger group and for men. In general, a longer period was required to rank women and older adults.

Conclusions: In a group of Japanese adults, coefficients of within-individual variation and between-individual variation, which were used to estimate the group size and number of records required for adequate dietary assessment, differed by age, sex, and nutrient.
\end{abstract}

Key words: nutrients; within- and between-individual variation; age; sex; Japanese

\section{INTRODUCTION}

Fluctuations in daily dietary intake values, which frequently hamper analysis of nutritional data, result from within- and between-individual variation. ${ }^{1-3}$ Within-individual variation is subject to several factors such as true day-to-day variation, variation by day of the week and season, and residual variation, including measurement error. Between-individual variation is strongly influenced by factors such as age and sex. ${ }^{1-8}$
These variations should be considered whenever dietary intake is assessed in individuals and groups. ${ }^{3,9}$ Properly designed nutritional research that includes dietary assessment should thus consider the number of subjects required in 1 group (group size) and the number of days required to implement the assessment efficiently. ${ }^{3,10}$ These variables can be estimated using within- and between-individual variation of nutrient intake. ${ }^{1-3,7}$ Dietary assessment is usually conducted for 1 of 3 purposes: (1) to compare the mean intake of 
different groups, (2) to rank individuals within a group, or (3) to assess an individual's usual intake. Thus, knowledge of within- and between-individual variation is required in order to determine group size in studies comparing mean intake between groups, ${ }^{7}$ and the ratio of within- to betweenindividual variation is required in order to determine the number of days required for dietary assessment in studies that assess diet-disease associations using rankings of subjects within a group (eg, in estimating relative risk using quartile categorizations). ${ }^{1,5,11}$ Moreover, within-individual variation influences the number of days required to assess the usual intake of individuals (eg, to establish the true nature of doseresponse). ${ }^{1,3,9}$

The magnitude of within- and between-individual variation in nutrient intake is largely determined by cultural and ecologic factors. ${ }^{2,3,12}$ The group size and number of days required for precise estimation of usual nutrient intake has been studied, but results have differed, ${ }^{7,13}$ and these variables might differ by age, sex, and country, due to different dietary habits. ${ }^{13}$ However, investigation of these issues has been limited in Japan. ${ }^{4,14,15}$

Here, we examined within- and between-individual variation in dietary intake by age and sex among Japanese adults. We assessed energy and 31 selected nutrients derived from dietary records (DRs) that were maintained for 4 nonconsecutive days in each season (16 days in total). We also estimated the group size required to estimate a group's mean intake and the number of days required to rank individuals within a group and to assess an individual's usual intake with adequate precision.

\section{METHODS}

\section{Subjects}

The study was conducted in 4 areas in Japan that differed in geographic conditions and dietary habits, namely Osaka (Osaka City: 11743 persons $/ \mathrm{km}^{2}$; urban), Nagano (Matsumoto City: 786 persons $/ \mathrm{km}^{2}$; rural inland), Tottori (Kurayoshi City: 285 persons $/ \mathrm{km}^{2}$; rural coastal), and Okinawa (Ginowan City: 4446 persons $/ \mathrm{km}^{2}$; urban island), ${ }^{16}$ between November 2002 and September 2003. ${ }^{17-20}$ We recruited apparently healthy women aged 30 to 69 years who were willing to participate with a cohabiting husband. The subjects were volunteers and were asked by local staff to participate in the study. Subject recruitment was continued until a sufficient number of participants was obtained. In each of the 4 areas, each 10 -year age band (30-39, 40-49, 50-59, and 60-69 years) included 8 women; the age of the husband was not considered. Thus, a total of 128 women and 128 men were invited. Dietitians were excluded from the study. None of the subjects had recently received dietary counseling from a doctor or dietitian or had a history of educational hospitalization for diabetes or nutritional education from a dietitian. Before the study, group orientations were held to explain the study purpose and design. Written informed consent was obtained from each subject. The study did not undergo ethical approval because it was conducted before ethical guidelines for epidemiologic research were enforced in Japan. However, use of data from this study was approved by the Ethics Committee at the University of Tokyo Faculty of Medicine (No. 3421). A total of 121 women aged 30 to 69 years and 121 men aged 30 to 76 years completed 16-day DRs and were included in the present analysis.

\section{Four 4-day semi-weighed dietary records}

Between November 2002 and September 2003, each subject completed one 4-nonconsecutive-day semi-weighed DR in each of the 4 seasons at intervals of approximately 3 months: DR1 in November/December 2002 (autumn), DR2 in February 2003 (winter), DR3 in May 2003 (spring), and DR4 in August/September 2003 (summer). ${ }^{17-20}$ The 4 recording days consisted of 3 randomly selected weekdays and 1 weekend day. During the orientation session, local staff (registered dietitians) gave subjects both written and verbal instructions on how to keep the dietary record, using a completed recording sheet as an example. Each couple was given blank recording sheets and a digital scale (Tanita $\mathrm{KD}-173, \pm 2 \mathrm{~g}$ precision for $0-250 \mathrm{~g}$ and $\pm 4 \mathrm{~g}$ precision for 251-1000 g). Subjects were also instructed on how to weigh each food item and drink and were asked to record and weigh all foods and drinks consumed on each recording day. When weighing was difficult (eg, when eating out), we instructed them to record the size and quantity of foods they ate as precisely as possible, using household measures. For each recording day, the subjects were asked to fax the completed forms to the local staff. The staff reviewed the submitted forms and, if necessary, asked the subject to augment and/or modify records by telephone or fax. The responses were faxed or, in some cases, handed directly to the staff.

All collected records were checked by trained registered dietitians in each local center and then again in the data center. The coding of records and conversion of measurements into grams were performed by trained registered dietitians in the survey center in accordance with uniform procedures. A total of 1398 food and beverage items appeared in the dietary records. Intake of energy and 31 selected nutrients was assessed based on the estimated intake of all items and the Standard Tables of Food Composition in Japan. ${ }^{21}$

\section{Anthropometric measurements, physical activity level, and reporting adequacy of reported energy intake}

Body height and weight were measured to the nearest $0.1 \mathrm{~cm}$ and $0.1 \mathrm{~kg}$, respectively, with subjects wearing light clothing and no shoes. Body mass index (BMI) was calculated as body weight $(\mathrm{kg})$ divided by the square of body height $(\mathrm{m})$. Basal metabolic rate (BMR) was calculated for each subject from age, measured body height, and weight with the use 
of the equations of Ganpule et al. ${ }^{22}$ Physical activity level (PAL) was obtained from a questionnaire that queried subjects on their occupation and leisure-time activity. PAL was classified into 1 of 4 categories, and the categorical classification of PAL was then converted to 1.5 for sedentary or light, 1.75 for active or moderate, and 2.0 for vigorous and heavy PAL (Ministry of Health, Labour and Welfare of Japan, 2009). ${ }^{23}$ Estimated energy requirement (EER) was calculated as the product of PAL and BMR. We used the ratio of reported energy intake (EI) to EER (EI/EER) as an indicator of the adequacy of energy intake reporting and defined a ratio of 1.0 as adequate reporting for the group.

\section{Statistical analysis}

All statistical analyses were performed separately for women and men in 2 age groups (younger: 30-49 years for both women and men; older: 50-69 years for women and 50-76 years for men) using SAS statistical software, version 9.2 (SAS Institute Inc., Cary, NC, USA). Means, coefficients of within-individual variation $\left(\mathrm{CV}_{\mathrm{w}}\right)$ and between-individual variation $\left(\mathrm{CV}_{\mathrm{b}}\right)$, variance ratio, required group size, and required number of days were compared between age groups and sexes.

Means, $\mathrm{SD}, \mathrm{CV}_{\mathrm{w}}$, and $\mathrm{CV}_{\mathrm{b}}$ for intakes were calculated. Variances of intake were estimated into 2 sources by 1-way ANOVA: (1) between-individual variance $\left(\sigma_{\mathrm{b}}{ }^{2}\right)$ and (2) within-individual variance $\left(\sigma_{\mathrm{w}}^{2}\right)$ (ie, day-to-day variation unaccounted for by other sources). Estimates of $\sigma_{\mathrm{w}}{ }^{2}$ and $\sigma_{\mathrm{b}}{ }^{2}$ were calculated by setting mean squares equal to their expected values.

We used untransformed data to analyze within- and between-individual variation in energy and all nutrients because a previous study showed that the estimated relative contribution of sources of variance was not considerably affected by logarithmic transformation ${ }^{2}$ and because other previous studies showed that a logarithm and Box-Cox transformation did not improve the assumption of homoscedasticity across covariates in the models, that estimates based upon transformed nutrient data were difficult to interpret meaningfully, and that back-transformation would introduce bias to variance estimates. ${ }^{24,25}$

The group size of DR $(\mathrm{G})$ required to estimate mean intakes with $95 \%$ CIs within the specified percentage deviation $\left(\mathrm{D}_{0}\right)$ of group mean from group usual ("true") mean intake was calculated using the following formula ${ }^{2}: \mathrm{G}=1.96^{2} \times\left[\left(\mathrm{CV}_{\mathrm{b}}{ }^{2}+\right.\right.$ $\left.\left.\mathrm{CV}_{\mathrm{w}}{ }^{2}\right) / \mathrm{D}_{0}^{2}\right]$.

The number of days of $\mathrm{DR}\left(\mathrm{N}_{\mathrm{R}}\right)$ required to ensure a specified level of correlation coefficient $(r)$ between observed and unobserved usual ("true") mean intakes in individuals was calculated using the following formula ${ }^{1,7}: N_{R}=$ $\left[r^{2} /\left(1-r^{2}\right)\right] \times V R$, where $V R$ is the variance ratio as determined by $\sigma_{\mathrm{w}}{ }^{2} / \sigma_{\mathrm{b}}{ }^{2}$. For this analysis, $\mathrm{r}$ is thus a measure of confidence of ranking or classification of individuals into fractions (eg, fourths).
Table 1. Characteristics of study subjects according to sex and age group

\begin{tabular}{|c|c|c|c|c|c|c|c|c|}
\hline & \multicolumn{4}{|c|}{ Women $(n=121)$} & \multicolumn{4}{|c|}{$\operatorname{Men}(n=121)$} \\
\hline & \multicolumn{2}{|c|}{$\begin{array}{l}\text { Younger }^{\mathrm{a}} \\
(n=58)\end{array}$} & \multicolumn{2}{|c|}{$\begin{array}{l}\text { Older }^{\mathrm{a}} \\
(n=63)\end{array}$} & \multicolumn{2}{|c|}{$\begin{array}{c}\text { Younger }^{\mathrm{a}} \\
(n=54)\end{array}$} & \multicolumn{2}{|c|}{$\begin{array}{l}\text { Older }^{\mathrm{a}} \\
(n=67)\end{array}$} \\
\hline & Mean & SD & Mean & SD & Mean & SD & Mean & SD \\
\hline Age (years) & 39.0 & 5.0 & 58.9 & 5.7 & 40.5 & 5.2 & 61.5 & 6.5 \\
\hline Body height (cm) & 156.6 & 5.7 & 152.8 & 6.1 & 170.3 & 6.1 & 165.1 & 6.0 \\
\hline Body weight (kg) & 52.9 & 6.9 & 53.8 & 7.2 & 67.9 & 11.1 & 65.2 & 9.6 \\
\hline BMI $\left(\mathrm{kg} / \mathrm{m}^{2}\right)$ & 21.6 & 2.8 & 23.0 & 2.7 & 23.4 & 3.2 & 23.8 & 2.7 \\
\hline BMR (kcal/day) & 1122 & 92 & 1046 & 111 & 1498 & 151 & 1368 & 145 \\
\hline Physical activity level & 1.67 & 0.13 & 1.65 & 0.13 & 1.73 & 0.22 & 1.68 & 0.17 \\
\hline El/EER & 0.97 & 0.15 & 1.08 & 0.18 & 0.94 & 0.21 & 1.03 & 0.18 \\
\hline
\end{tabular}

Abbreviations: $\mathrm{BMI}=$ body mass index; $\mathrm{BMR}=$ basal metabolic rate; $\mathrm{EI}=$ energy intake; EER = estimated energy requirement.

aYounger: 30-49 years for women and men; older: 50-69 years for women and $50-76$ years for men.

The number of days of DR $\left(\mathrm{N}_{\mathrm{I}}\right)$ required to estimate mean intakes with $95 \%$ CIs within the specified percentage deviation $\left(\mathrm{D}_{1}\right)$ of individual mean from usual ("true") mean intake based on $\mathrm{CV}_{\mathrm{w}}$ was calculated using the following formula ${ }^{1-3}: \mathrm{N}_{\mathrm{I}}=\left(1.96 \times \mathrm{CV}_{\mathrm{w}} / \mathrm{D}_{1}\right)^{2}$.

\section{RESULTS}

Table 1 shows the physical characteristics of men and women in the 2 age groups. The mean value of EI/EER was around 1.0 in all groups; the smallest value, 0.94, was for younger men, and largest value, 1.08, was for older women.

Table 2 shows means, $\mathrm{SD}, \mathrm{CV}_{\mathrm{w}}, \mathrm{CV}_{\mathrm{b}}$, and $\mathrm{VR}$ of daily intake of energy and 31 selected nutrients. Mean intake was larger in the older than in the younger group in both sexes for most nutrients and larger in men than in women for energy and all nutrients. $\mathrm{CV}_{\mathrm{w}}$ was larger than $\mathrm{CV}_{\mathrm{b}}$ for energy and most nutrients irrespective of age or sex. $\mathrm{CV}_{\mathrm{w}}$ was larger in the younger than in the older group for both women (for energy and 26 nutrients; $\pm 1 \%-65 \%$ differences) and men (for energy and 28 nutrients; $\pm 2 \%-25 \%$ differences). The findings for $\mathrm{CV}_{\mathrm{b}}$ were similar among both women (for energy and 26 nutrients; $\pm 5 \%-12 \%$ differences) and men (for energy and 29 nutrients; $\pm 8 \%-11 \%$ differences). Additionally, $\mathrm{CV}_{\mathrm{w}}$ was larger in men than in women for both the younger (for energy and 21 nutrients; $\pm 8 \%-4 \%$ differences) and older groups (for energy and 22 nutrients; $\pm 7 \%-51 \%$ differences). Similar findings were obtained in $\mathrm{CV}_{\mathrm{b}}$ for both the younger (for energy and 29 nutrients; $\pm 1 \%-8 \%$ differences) and older groups (for energy and 18 nutrients; $\pm 4 \%-8 \%$ differences). VR was greater than 1 for all except water (in younger women and men and older men) and carbohydrate (in younger men). In contrast to the results for $\mathrm{CV}_{\mathrm{w}}$ and $\mathrm{CV}_{\mathrm{b}}$, VR was larger in the older than in the younger group for both women (for energy and 21 nutrients) and men (for energy and 26 nutrients) and larger in women than in men for both the younger (for energy and 27 nutrients) and older groups (for energy and 16 nutrients). 
Table 2. Mean daily energy and nutrient intake, coefficients of variation, and within- to between-individual variance ratios according to sex and age group

\begin{tabular}{|c|c|c|c|c|c|c|c|c|c|c|c|c|c|c|c|c|c|c|c|c|}
\hline & \multicolumn{10}{|c|}{ Women $(n=121)$} & \multicolumn{10}{|c|}{ Men $(n=121)$} \\
\hline & \multicolumn{5}{|c|}{ Younger $^{\mathrm{a}}(n=58)$} & \multicolumn{5}{|c|}{ Older $^{\mathrm{a}}(n=63)$} & \multicolumn{5}{|c|}{ Younger $^{\mathrm{a}}(n=54)$} & \multicolumn{5}{|c|}{ Older $^{\mathrm{a}}(n=67)$} \\
\hline & Mean & SD & $\begin{array}{l}C V_{w} \\
(\%)^{b}\end{array}$ & $\begin{array}{l}C V_{b} \\
(\%)^{c}\end{array}$ & $V^{d}$ & Mean & SD & $\begin{array}{l}\mathrm{CV}_{\mathrm{w}} \\
(\%)^{\mathrm{b}}\end{array}$ & $\begin{array}{l}\mathrm{CV}_{\mathrm{b}} \\
(\%)^{\mathrm{c}}\end{array}$ & $V^{d}$ & Mean & SD & $\begin{array}{l}\mathrm{CV}_{\mathrm{w}} \\
(\%)^{\mathrm{b}}\end{array}$ & $\begin{array}{l}C V_{b} \\
(\%)^{c}\end{array}$ & $V^{d}$ & Mean & SD & $\begin{array}{l}\mathrm{CV}_{\mathrm{w}} \\
(\%)^{\mathrm{b}}\end{array}$ & $\begin{array}{l}\mathrm{CV}_{\mathrm{b}} \\
(\%)^{\mathrm{c}}\end{array}$ & $V^{d}$ \\
\hline Energy (kcal) & 1824 & 327 & 20.6 & 17.2 & 1.44 & 1845 & 246 & 18.3 & 12.5 & 2.15 & 2392 & 473 & 21.1 & 19.0 & 1.23 & 2330 & 370 & 18.5 & 15.2 & 1.49 \\
\hline Protein (g) & 65.1 & 11.6 & 25.5 & 16.6 & 2.37 & 72.9 & 10.6 & 23.5 & 13.4 & 3.08 & 81.0 & 16.9 & 25.4 & 19.8 & 1.64 & 86.8 & 13.6 & 23.7 & 14.5 & 2.67 \\
\hline Fat $(\mathrm{g})$ & 59.7 & 12.6 & 35.0 & 19.3 & 3.28 & 54.6 & 9.4 & 34.9 & 15.0 & 5.43 & 71.6 & 18.2 & 37.0 & 23.6 & 2.45 & 63.1 & 12.3 & 35.9 & 17.3 & 4.30 \\
\hline Carbohydrate (g) & 244 & 51 & 20.6 & 20.4 & 1.02 & 258 & 41 & 18.5 & 15.1 & 1.50 & 311 & 69 & 20.9 & 21.6 & 0.93 & 312 & 52 & 19.9 & 15.9 & 1.57 \\
\hline Dietary fiber $(\mathrm{g})$ & 12.4 & 3.2 & 33.8 & 24.8 & 1.86 & 16.8 & 3.9 & 32.4 & 21.8 & 2.22 & 13.3 & 3.7 & 34.1 & 26.5 & 1.65 & 17.4 & 4.1 & 30.5 & 22.1 & 1.90 \\
\hline Water (g) & 1902 & 403 & 20.6 & 20.6 & 1.00 & 2161 & 483 & 17.0 & 22.0 & 0.60 & 2356 & 615 & 23.3 & 25.5 & 0.84 & 2476 & 498 & 18.6 & 19.6 & 0.90 \\
\hline Sodium (mg) & 3742 & 734 & 33.7 & 17.7 & 3.61 & 4315 & 780 & 34.4 & 15.9 & 4.67 & 4574 & 1008 & 35.7 & 20.2 & 3.13 & 5053 & 860 & 34.1 & 14.7 & 5.35 \\
\hline Potassium (mg) & 2322 & 519 & 27.4 & 21.3 & 1.66 & 2994 & 548 & 26.7 & 17.0 & 2.46 & 2676 & 661 & 26.0 & 23.8 & 1.19 & 3207 & 571 & 23.9 & 16.8 & 2.03 \\
\hline Calcium (mg) & 507 & 152 & 38.8 & 28.3 & 1.88 & 628 & 164 & 34.3 & 24.7 & 1.93 & 534 & 196 & 40.0 & 35.4 & 1.28 & 637 & 166 & 34.7 & 24.6 & 2.00 \\
\hline Magnesium (mg) & 240 & 48 & 28.4 & 18.7 & 2.31 & 306 & 56 & 26.6 & 17.1 & 2.41 & 286 & 67 & 27.0 & 22.4 & 1.45 & 343 & 62 & 25.6 & 17.0 & 2.28 \\
\hline Phosphorus (mg) & 983 & 197 & 24.6 & 19.1 & 1.65 & 1138 & 192 & 22.4 & 15.9 & 1.98 & 1187 & 275 & 24.0 & 22.4 & 1.15 & 1313 & 219 & 22.7 & 15.7 & 2.10 \\
\hline Iron (mg) & 7.2 & 1.4 & 35.1 & 17.4 & 4.07 & 9.2 & 2.0 & 33.1 & 20.4 & 2.62 & 8.4 & 1.9 & 35.1 & 21.3 & 2.71 & 10.1 & 1.8 & 31.3 & 16.2 & 3.74 \\
\hline Zinc (mg) & 7.7 & 1.5 & 31.4 & 17.6 & 3.19 & 8.3 & 1.3 & 28.1 & 13.6 & 4.28 & 9.8 & 2.2 & 32.4 & 21.2 & 2.34 & 10.0 & 1.6 & 30.3 & 13.8 & 4.86 \\
\hline$\beta$-carotene equivalent ${ }^{\mathrm{e}}(\mu \mathrm{g})$ & 2891 & 1036 & 84.4 & 29.0 & 8.48 & 4345 & 1334 & 62.0 & 26.5 & 5.48 & 3252 & 1130 & 80.0 & 28.4 & 7.91 & 4475 & 1377 & 65.9 & 26.0 & 6.44 \\
\hline Vitamin $A^{f}(\mu g R E)$ & 608 & 402 & 223.9 & 35.2 & 40.49 & 702 & 324 & 158.6 & 23.7 & 44.87 & 648 & 450 & 221.9 & 41.9 & 28.02 & 827 & 504 & 209.4 & 31.2 & 45.08 \\
\hline Vitamin D $(\mu \mathrm{g})$ & 6.0 & 2.2 & 105.6 & 25.3 & 17.38 & 9.4 & 3.7 & 99.9 & 30.6 & 10.66 & 7.4 & 2.7 & 106.0 & 24.4 & 18.82 & 11.3 & 4.5 & 93.3 & 32.0 & 8.52 \\
\hline$\alpha$-tocopherol (mg) & 6.9 & 1.5 & 36.5 & 20.1 & 3.30 & 7.9 & 1.5 & 36.9 & 16.3 & 5.12 & 8.0 & 2.0 & 39.9 & 23.0 & 3.01 & 8.8 & 1.8 & 38.1 & 17.7 & 4.65 \\
\hline Vitamin $\mathrm{K}(\mu \mathrm{g})$ & 203 & 75 & 68.7 & 32.7 & 4.43 & 269 & 90 & 57.0 & 30.4 & 3.51 & 215 & 78 & 60.7 & 32.8 & 3.43 & 275 & 88 & 63.0 & 27.9 & 5.12 \\
\hline Vitamin $B_{1}(\mathrm{mg})$ & 0.8 & 0.2 & 41.2 & 17.8 & 5.32 & 0.9 & 0.2 & 34.1 & 14.3 & 5.71 & 1.0 & 0.2 & 44.9 & 21.0 & 4.57 & 1.1 & 0.2 & 36.5 & 14.6 & 6.30 \\
\hline Vitamin $B_{2}(\mathrm{mg})$ & 1.2 & 0.3 & 38.1 & 20.2 & 3.55 & 1.4 & 0.3 & 28.9 & 19.2 & 2.26 & 1.4 & 0.4 & 36.3 & 24.2 & 2.26 & 1.6 & 0.3 & 33.0 & 17.4 & 3.59 \\
\hline Niacin $(\mathrm{mg})$ & 15.9 & 3.6 & 38.5 & 20.4 & 3.57 & 18.3 & 3.7 & 34.7 & 18.3 & 3.58 & 21.6 & 5.8 & 39.4 & 24.8 & 2.51 & 22.6 & 5.6 & 36.4 & 23.2 & 2.47 \\
\hline Vitamin $\mathrm{B}_{6}(\mathrm{mg})$ & 1.1 & 0.2 & 33.4 & 20.0 & 2.78 & 1.4 & 0.3 & 28.6 & 17.2 & 2.76 & 1.4 & 0.4 & 34.9 & 24.8 & 1.97 & 1.6 & 0.3 & 30.0 & 18.8 & 2.55 \\
\hline Vitamin $B_{12}(\mu \mathrm{g})$ & 6.4 & 2.6 & 103.8 & 30.3 & 11.73 & 8.7 & 3.0 & 88.6 & 26.0 & 11.63 & 8.0 & 3.6 & 96.1 & 38.5 & 6.23 & 10.9 & 4.2 & 96.4 & 29.7 & 10.54 \\
\hline Folate $(\mu \mathrm{g})$ & 300 & 82 & 51.8 & 24.0 & 4.67 & 411 & 97 & 39.1 & 21.4 & 3.33 & 339 & 96 & 53.6 & 25.0 & 4.58 & 451 & 103 & 49.6 & 19.2 & 6.69 \\
\hline Vitamin C (mg) & 87.7 & 29.7 & 52.0 & 31.3 & 2.76 & 136.7 & 34.8 & 43.4 & 23.0 & 3.54 & 94.3 & 36.8 & 53.1 & 36.7 & 2.10 & 140.4 & 40.8 & 50.4 & 26.2 & 3.70 \\
\hline SFA (g) & 17.3 & 4.3 & 40.9 & 22.6 & 3.28 & 15.1 & 3.2 & 40.8 & 18.8 & 4.71 & 20.2 & 6.4 & 45.1 & 29.7 & 2.31 & 16.9 & 3.5 & 41.3 & 18.2 & 5.16 \\
\hline MUFA (g) & 21.6 & 5.0 & 40.7 & 20.8 & 3.85 & 18.8 & 3.7 & 41.2 & 17.0 & 5.90 & 26.6 & 7.0 & 42.5 & 24.2 & 3.09 & 22.3 & 5.3 & 42.4 & 21.1 & 4.02 \\
\hline PUFA (g) & 12.9 & 2.4 & 40.3 & 15.9 & 6.42 & 12.8 & 2.3 & 40.1 & 14.9 & 7.21 & 15.9 & 3.5 & 40.7 & 19.2 & 4.47 & 14.8 & 3.0 & 39.7 & 17.8 & 5.00 \\
\hline n-6 PUFA (g) & 10.7 & 2.1 & 42.0 & 16.2 & 6.69 & 10.2 & 1.9 & 43.3 & 14.9 & 8.45 & 13.0 & 2.9 & 42.8 & 19.5 & 4.80 & 11.7 & 2.5 & 42.6 & 18.6 & 5.26 \\
\hline n-3 PUFA (g) & 2.2 & 0.5 & 55.9 & 20.0 & 7.82 & 2.6 & 0.6 & 57.1 & 19.0 & 9.02 & 2.8 & 0.7 & 57.0 & 22.3 & 6.51 & 3.1 & 0.8 & 57.8 & 21.2 & 7.47 \\
\hline Marine origin n-3 PUFAg $(\mathrm{mg})$ & 687 & 289 & 119.5 & 29.6 & 16.32 & 1030 & 392 & 104.1 & 27.7 & 14.15 & 900 & 411 & 123.9 & 33.6 & 13.57 & 1312 & 524 & 99.0 & 31.4 & 9.94 \\
\hline Cholesterol (mg) & 330 & 83 & 52.8 & 21.6 & 5.97 & 332 & 79 & 51.3 & 20.0 & 6.60 & 397 & 103 & 49.0 & 23.0 & 4.54 & 398 & 103 & 47.6 & 23.0 & 4.28 \\
\hline
\end{tabular}

Abbreviations: $\mathrm{CV}_{\mathrm{w}}=$ coefficient of within-individual variation; $\mathrm{CV}_{\mathrm{b}}=$ coefficient of between-individual variation; $\mathrm{VR}=$ ratio of within- to betweenindividual variance; RE = retinol equivalents; SFA = saturated fatty acids; MUFA = monounsaturated fatty acids; PUFA = polyunsaturated fatty acids.

aYounger: 30-49 years for women and men; older: 50-69 years for women and 50-76 years for men.

${ }^{\mathrm{b}} \mathrm{CV}_{\mathrm{w}}=\left[(\text { within-individual variance })^{0.5} /\right.$ mean $] \times 100$.

${ }^{\mathrm{c}} \mathrm{CV}_{\mathrm{b}}=[\text { (between-individual variance })^{0.5} /$ mean $] \times 100$.

dVR $=$ within-individual/between-individual variance ratio $\left(\sigma_{\mathrm{w}}{ }^{2} / \sigma_{\mathrm{b}}{ }^{2}\right)$.

esum of $\beta$-carotene, $\alpha$-carotene/2, and cryptoxanthin/2.

fSum of retinol, $\beta$-carotene/12, $\alpha$-carotene/24, and cryptoxanthin/24.

gSum of eicosapentaenoic acid, docosapentaenoic acid, and docosahexaenoic acid.

Table 3 shows the group size required to estimate mean intake of energy and nutrients with $95 \%$ CIs within a specified (ie, $2.5 \%, 5 \%, 10 \%$, and $20 \%$ ) deviation of a group's mean from the group's usual ("true") mean intake by DR. The group size required to determine the mean intake of the group was larger in the younger than in the older group for both women (for energy and 29 nutrients) and men (for energy and 30 nutrients) and was larger in men than in women for both the younger (for energy and 26 nutrients) and the older groups (for energy and 22 nutrients).

Table 4 presents the number of days required to ensure specified (ie, 0.75, 0.80, 0.85, 0.90, and 0.95) correlation coefficients between observed and usual ("true") mean intake of energy and nutrients by DR. The number of days required to rank individuals within a group by intake was larger in the older than in the younger group for both women (for energy and 20 nutrients) and men (for energy and 25 nutrients) and was larger in women than in men for both the younger (for energy and 29 nutrients) and older groups (for energy and 16 nutrients).

Table 5 shows the number of days required to assess mean intake of energy and nutrients with $95 \%$ CIs within a specified (ie, $5 \%, 10 \%, 20 \%$, and $30 \%$ ) deviation of an individual's mean from usual ("true") mean intake by DR. The number of days needed to assess the usual intake of individuals was larger in the younger than in the older group for both women (for energy and 26 nutrients) and men (for energy and 28 nutrients) and was larger in men than in women for both the younger (for energy and 20 nutrients) and older groups (for energy and 21 nutrients).

\section{DISCUSSION}

In this study of Japanese women and men, we found that coefficients of within-individual variation and betweenindividual variation were generally larger in the younger 
Table 3. Group size required to estimate mean intake of energy and nutrients with $95 \%$ Cls within the specified $\%$ deviation $\left(D_{0}\right)$ of a group's mean from the group's usual ("true") mean intake by dietary record according to sex and age groupa

\begin{tabular}{|c|c|c|c|c|c|c|c|c|c|c|c|c|c|c|c|c|}
\hline \multirow[b]{3}{*}{$\mathrm{D}_{0}$} & \multicolumn{8}{|c|}{ Women $(n=121)$} & \multicolumn{8}{|c|}{ Men $(n=121)$} \\
\hline & \multicolumn{4}{|c|}{ Younger $^{\mathrm{b}}(n=58)$} & \multicolumn{4}{|c|}{$\operatorname{Older}^{\mathrm{b}}(n=63)$} & \multicolumn{4}{|c|}{ Younger $^{b}(n=54)$} & \multicolumn{4}{|c|}{$\operatorname{Older}^{\mathrm{b}}(n=67)$} \\
\hline & $2.5 \%$ & $5 \%$ & $10 \%$ & $20 \%$ & $2.5 \%$ & $5 \%$ & $10 \%$ & $20 \%$ & $2.5 \%$ & $5 \%$ & $10 \%$ & $20 \%$ & $2.5 \%$ & $5 \%$ & $10 \%$ & $20 \%$ \\
\hline Energy & 442 & 111 & 28 & 7 & 302 & 76 & 19 & 5 & 497 & 124 & 31 & 8 & 353 & 88 & 22 & 6 \\
\hline Protein & 569 & 142 & 36 & 9 & 448 & 112 & 28 & 7 & 639 & 160 & 40 & 10 & 476 & 119 & 30 & 7 \\
\hline Fat & 980 & 245 & 61 & 15 & 884 & 221 & 55 & 14 & 1186 & 297 & 74 & 19 & 976 & 244 & 61 & 15 \\
\hline Carbohydrate & 517 & 129 & 32 & 8 & 352 & 88 & 22 & 5 & 556 & 139 & 35 & 9 & 400 & 100 & 25 & 6 \\
\hline Dietary fiber & 1081 & 270 & 68 & 17 & 937 & 234 & 59 & 15 & 1145 & 286 & 72 & 18 & 872 & 218 & 54 & 14 \\
\hline Water & 520 & 130 & 32 & 8 & 473 & 118 & 30 & 7 & 732 & 183 & 46 & 11 & 448 & 112 & 28 & 7 \\
\hline Sodium & 889 & 222 & 56 & 14 & 881 & 220 & 55 & 14 & 1032 & 258 & 64 & 16 & 846 & 212 & 53 & 13 \\
\hline Potassium & 741 & 185 & 46 & 12 & 618 & 155 & 39 & 10 & 764 & 191 & 48 & 12 & 524 & 131 & 33 & 8 \\
\hline Calcium & 1416 & 354 & 88 & 22 & 1096 & 274 & 69 & 17 & 1752 & 438 & 109 & 27 & 1110 & 278 & 69 & 17 \\
\hline Magnesium & 712 & 178 & 44 & 11 & 614 & 154 & 38 & 10 & 757 & 189 & 47 & 12 & 580 & 145 & 36 & 9 \\
\hline Phosphorus & 596 & 149 & 37 & 9 & 464 & 116 & 29 & 7 & 661 & 165 & 41 & 10 & 467 & 117 & 29 & 7 \\
\hline Iron & 946 & 236 & 59 & 15 & 929 & 232 & 58 & 15 & 1038 & 260 & 65 & 16 & 763 & 191 & 48 & 12 \\
\hline Zinc & 794 & 198 & 50 & 12 & 598 & 149 & 37 & 9 & 921 & 230 & 58 & 14 & 682 & 170 & 43 & 11 \\
\hline$\beta$-carotene equivalent ${ }^{c}$ & 4889 & 1222 & 306 & 76 & 2793 & 698 & 175 & 44 & 4426 & 1106 & 277 & 69 & 3085 & 771 & 193 & 48 \\
\hline Vitamin $A^{d}$ & 31569 & 7892 & 1973 & 493 & 15808 & 3952 & 988 & 247 & 31332 & 7833 & 1958 & 490 & 27544 & 6886 & 1722 & 430 \\
\hline Vitamin D & 7246 & 1812 & 453 & 113 & 6715 & 1679 & 420 & 105 & 7279 & 1820 & 455 & 114 & 5977 & 1494 & 374 & 93 \\
\hline$\alpha$-tocopherol & 1068 & 267 & 67 & 17 & 1002 & 250 & 63 & 16 & 1303 & 326 & 81 & 20 & 1085 & 271 & 68 & 17 \\
\hline Vitamin $\mathrm{K}$ & 3558 & 890 & 222 & 56 & 2568 & 642 & 161 & 40 & 2925 & 731 & 183 & 46 & 2919 & 730 & 182 & 46 \\
\hline Vitamin $\mathrm{B}_{1}$ & 1237 & 309 & 77 & 19 & 842 & 210 & 53 & 13 & 1511 & 378 & 94 & 24 & 951 & 238 & 59 & 15 \\
\hline Vitamin $B_{2}$ & 1141 & 285 & 71 & 18 & 738 & 184 & 46 & 12 & 1171 & 293 & 73 & 18 & 854 & 214 & 53 & 13 \\
\hline Niacin & 1168 & 292 & 73 & 18 & 946 & 237 & 59 & 15 & 1331 & 333 & 83 & 21 & 1147 & 287 & 72 & 18 \\
\hline Vitamin $\mathrm{B}_{6}$ & 933 & 233 & 58 & 15 & 687 & 172 & 43 & 11 & 1127 & 282 & 70 & 18 & 770 & 193 & 48 & 12 \\
\hline Vitamin $\mathrm{B}_{12}$ & 7191 & 1798 & 449 & 112 & 5235 & 1309 & 327 & 82 & 6585 & 1646 & 412 & 103 & 6254 & 1563 & 391 & 98 \\
\hline Folate & 2001 & 500 & 125 & 31 & 1219 & 305 & 76 & 19 & 2147 & 537 & 134 & 34 & 1741 & 435 & 109 & 27 \\
\hline Vitamin C & 2261 & 565 & 141 & 35 & 1483 & 371 & 93 & 23 & 2564 & 641 & 160 & 40 & 1980 & 495 & 124 & 31 \\
\hline SFA & 1344 & 336 & 84 & 21 & 1243 & 311 & 78 & 19 & 1789 & 447 & 112 & 28 & 1251 & 313 & 78 & 20 \\
\hline MUFA & 1284 & 321 & 80 & 20 & 1222 & 305 & 76 & 19 & 1471 & 368 & 92 & 23 & 1378 & 344 & 86 & 22 \\
\hline PUFA & 1155 & 289 & 72 & 18 & 1127 & 282 & 70 & 18 & 1245 & 311 & 78 & 19 & 1162 & 291 & 73 & 18 \\
\hline n-6 PUFA & 1244 & 311 & 78 & 19 & 1290 & 323 & 81 & 20 & 1362 & 341 & 85 & 21 & 1326 & 332 & 83 & 21 \\
\hline n-3 PUFA & 2170 & 543 & 136 & 34 & 2224 & 556 & 139 & 35 & 2301 & 575 & 144 & 36 & 2332 & 583 & 146 & 36 \\
\hline Marine origin $n-3 P U_{F}{ }^{e}$ & 9315 & 2329 & 582 & 146 & 7134 & 1784 & 446 & 111 & 10124 & 2531 & 633 & 158 & 6624 & 1656 & 414 & 103 \\
\hline Cholesterol & 2000 & 500 & 125 & 31 & 1862 & 465 & 116 & 29 & 1803 & 451 & 113 & 28 & 1715 & 429 & 107 & 27 \\
\hline
\end{tabular}

Abbreviations: SFA = saturated fatty acids; MUFA = monounsaturated fatty acids; PUFA = polyunsaturated fatty acids.

${ }^{a}$ Group size of dietary record assuming single observation for each individual $=1.96^{2} \times\left[\left(C_{b}{ }^{2}+C V_{w}{ }^{2}\right) / D_{0}{ }^{2}\right]$, where $D_{0}=$ the specified $\%$ deviation of group mean from group usual ("true") mean intake.

bYounger: 30-49 years for women and men; older: 50-69 years for women and 50-76 years for men.

'Sum of $\beta$-carotene, $\alpha$-carotene/2, and cryptoxanthin/ 2 .

dSum of retinol, $\beta$-carotene/12, $\alpha$-carotene/24, and cryptoxanthin/24.

eSum of eicosapentaenoic acid, docosapentaenoic acid, and docosahexaenoic acid.

group than in the older group, whereas variance ratio was larger in the older group than in the younger group. Similarly, both $\mathrm{CV}_{\mathrm{w}}$ and $\mathrm{CV}_{\mathrm{b}}$ were generally larger in men than in women, whereas VR was larger in women than in men. To our knowledge, this study is the first to examine within- and between-individual variation in dietary intake with respect to both age and sex in a Japanese population and in Asian men.

The results of this study are comparable with those of previous studies in Japan, ${ }^{4,14,15}$ namely, $\mathrm{CV}_{\mathrm{w}}$ was larger than $\mathrm{CV}_{\mathrm{b}}$, and $\mathrm{CV}_{\mathrm{w}}, \mathrm{CV}_{\mathrm{b}}$, and $\mathrm{VR}$ were relatively small for energy, carbohydrate, protein, and water, intermediate for minerals, dietary fiber, and fat, and large for fatty acids, cholesterol, and vitamins. Ogawa et al used four 3-day DRs to investigate women (aged 47-76 years) and men (aged 45-77 years) living in a rural area. ${ }^{15}$ Their results for $\mathrm{CV}_{\mathrm{w}}$ and $\mathrm{CV}_{\mathrm{b}}$ were similar to our estimates. Egami et al used four 4-day DRs to assess women and men (aged $>40$ years) living in a coastal area. ${ }^{14}$ $\mathrm{CV}_{\mathrm{w}}$ was generally larger than in our results, whereas $\mathrm{CV}_{\mathrm{b}}$ was smaller. Tokudome et al used four 7-day DRs to investigate female dietitians (aged 32-66 years). ${ }^{4} \mathrm{CV}_{\mathrm{w}}$ and $\mathrm{CV}_{\mathrm{b}}$ were generally smaller than in our study, possibly due to differences in eating patterns between their and our groups, which arose from the greater nutritional knowledge of their subjects.

Our findings are also consistent with those of several studies that examined $\mathrm{CV}_{\mathrm{w}}$ and $\mathrm{CV}_{\mathrm{b}}$ by age or sex. ${ }^{7,15,26}$ In a study of UK adults (a comparison among 4 groups categorized by sex and age, with younger groups aged 18-57 years using 7-day DRs vs older groups aged 60-80 years using three 7day DRs), $C V_{\mathrm{w}}$ and $\mathrm{CV}_{\mathrm{b}}$ were larger in the younger than in the older group for both sexes. ${ }^{7}$ In studies of Japanese adults living in a rural area (mentioned above), ${ }^{15} \mathrm{UK}$ adults (mentioned above), ${ }^{7}$ and US elderly adults (aged $>60$ years using 3-day DRs), ${ }^{26} \mathrm{CV}_{\mathrm{w}}$ and $\mathrm{CV}_{\mathrm{b}}$ were larger in men than in women. In a study of Chinese women (aged 40-59 years vs $60-70$ years using $24-\mathrm{h}$ dietary recall), while $\mathrm{CV}_{\mathrm{w}}$ was 
Table 4. Number of days required to ensure a specified correlation coefficient ( $r$ ) between observed and usual ("true") mean intake of energy and nutrients by dietary record according to sex and age group ${ }^{a}$

\begin{tabular}{|c|c|c|c|c|c|c|c|c|c|c|c|c|c|c|c|c|c|c|c|c|}
\hline \multirow[b]{3}{*}{$r$} & \multicolumn{10}{|c|}{ Women $(n=121)$} & \multicolumn{10}{|c|}{$\operatorname{Men}(n=121)$} \\
\hline & \multicolumn{5}{|c|}{ Youngerb $^{\mathrm{b}}(n=58)$} & \multicolumn{5}{|c|}{$\operatorname{Older}^{\mathrm{b}}(n=63)$} & \multicolumn{5}{|c|}{ Younger $^{\mathrm{b}}(n=54)$} & \multicolumn{5}{|c|}{$\operatorname{Older}^{\mathrm{b}}(n=67)$} \\
\hline & 0.75 & 0.8 & 0.85 & 0.9 & 0.95 & 0.75 & 0.8 & 0.85 & 0.9 & 0.95 & 0.75 & 0.8 & 0.85 & 0.9 & 0.95 & 0.75 & 0.8 & 0.85 & 0.9 & 0.95 \\
\hline Energy & 2 & 3 & 4 & 6 & 13 & 3 & 4 & 6 & 9 & 20 & 2 & 2 & 3 & 5 & 11 & 2 & 3 & 4 & 6 & 14 \\
\hline Protein & 3 & 4 & 6 & 10 & 22 & 4 & 5 & 8 & 13 & 28 & 2 & 3 & 4 & 7 & 15 & 3 & 5 & 7 & 11 & 25 \\
\hline Fat & 4 & 6 & 9 & 14 & 30 & 7 & 10 & 14 & 23 & 50 & 3 & 4 & 6 & 10 & 23 & 6 & 8 & 11 & 18 & 40 \\
\hline Carbohydrate & 1 & 2 & 3 & 4 & 9 & 2 & 3 & 4 & 6 & 14 & 1 & 2 & 2 & 4 & 9 & 2 & 3 & 4 & 7 & 15 \\
\hline Dietary fiber & 2 & 3 & 5 & 8 & 17 & 3 & 4 & 6 & 9 & 21 & 2 & 3 & 4 & 7 & 15 & 2 & 3 & 5 & 8 & 18 \\
\hline Water & 1 & 2 & 3 & 4 & 9 & 1 & 1 & 2 & 3 & 6 & 1 & 1 & 2 & 4 & 8 & 1 & 2 & 2 & 4 & 8 \\
\hline Sodium & 5 & 6 & 9 & 15 & 33 & 6 & 8 & 12 & 20 & 43 & 4 & 6 & 8 & 13 & 29 & 7 & 10 & 14 & 23 & 49 \\
\hline Potassium & 2 & 3 & 4 & 7 & 15 & 3 & 4 & 6 & 10 & 23 & 2 & 2 & 3 & 5 & 11 & 3 & 4 & 5 & 9 & 19 \\
\hline Calcium & 2 & 3 & 5 & 8 & 17 & 2 & 3 & 5 & 8 & 18 & 2 & 2 & 3 & 5 & 12 & 3 & 4 & 5 & 9 & 18 \\
\hline Magnesium & 3 & 4 & 6 & 10 & 21 & 3 & 4 & 6 & 10 & 22 & 2 & 3 & 4 & 6 & 13 & 3 & 4 & 6 & 10 & 21 \\
\hline Phosphorus & 2 & 3 & 4 & 7 & 15 & 3 & 4 & 5 & 8 & 18 & 1 & 2 & 3 & 5 & 11 & 3 & 4 & 5 & 9 & 19 \\
\hline Iron & 5 & 7 & 11 & 17 & 38 & 3 & 5 & 7 & 11 & 24 & 3 & 5 & 7 & 12 & 25 & 5 & 7 & 10 & 16 & 35 \\
\hline Zinc & 4 & 6 & 8 & 14 & 29 & 6 & 8 & 11 & 18 & 40 & 3 & 4 & 6 & 10 & 22 & 6 & 9 & 13 & 21 & 45 \\
\hline$\beta$-carotene equivalent ${ }^{c}$ & 11 & 15 & 22 & 36 & 79 & 7 & 10 & 14 & 23 & 51 & 10 & 14 & 21 & 34 & 73 & 8 & 11 & 17 & 27 & 60 \\
\hline Vitamin $A^{d}$ & 52 & 72 & 105 & 173 & 375 & 58 & 80 & 117 & 191 & 415 & 36 & 50 & 73 & 119 & 259 & 58 & 80 & 117 & 192 & 417 \\
\hline Vitamin D & 22 & 31 & 45 & 74 & 161 & 14 & 19 & 28 & 45 & 99 & 24 & 33 & 49 & 80 & 174 & 11 & 15 & 22 & 36 & 79 \\
\hline$\alpha$-tocopherol & 4 & 6 & 9 & 14 & 31 & 7 & 9 & 13 & 22 & 47 & 4 & 5 & 8 & 13 & 28 & 6 & 8 & 12 & 20 & 43 \\
\hline Vitamin $\mathrm{K}$ & 6 & 8 & 12 & 19 & 41 & 5 & 6 & 9 & 15 & 32 & 4 & 6 & 9 & 15 & 32 & 7 & 9 & 13 & 22 & 47 \\
\hline Vitamin $B_{1}$ & 7 & 9 & 14 & 23 & 49 & 7 & 10 & 15 & 24 & 53 & 6 & 8 & 12 & 19 & 42 & 8 & 11 & 16 & 27 & 58 \\
\hline Vitamin $B_{2}$ & 5 & 6 & 9 & 15 & 33 & 3 & 4 & 6 & 10 & 21 & 3 & 4 & 6 & 10 & 21 & 5 & 6 & 9 & 15 & 33 \\
\hline Niacin & 5 & 6 & 9 & 15 & 33 & 5 & 6 & 9 & 15 & 33 & 3 & 4 & 7 & 11 & 23 & 3 & 4 & 6 & 11 & 23 \\
\hline Vitamin $B_{6}$ & 4 & 5 & 7 & 12 & 26 & 4 & 5 & 7 & 12 & 26 & 3 & 4 & 5 & 8 & 18 & 3 & 5 & 7 & 11 & 24 \\
\hline Vitamin $\mathrm{B}_{12}$ & 15 & 21 & 31 & 50 & 109 & 15 & 21 & 30 & 50 & 108 & 8 & 11 & 16 & 27 & 58 & 14 & 19 & 27 & 45 & 98 \\
\hline Folate & 6 & 8 & 12 & 20 & 43 & 4 & 6 & 9 & 14 & 31 & 6 & 8 & 12 & 20 & 42 & 9 & 12 & 17 & 29 & 62 \\
\hline Vitamin C & 4 & 5 & 7 & 12 & 26 & 5 & 6 & 9 & 15 & 33 & 3 & 4 & 5 & 9 & 19 & 5 & 7 & 10 & 16 & 34 \\
\hline SFA & 4 & 6 & 9 & 14 & 30 & 6 & 8 & 12 & 20 & 44 & 3 & 4 & 6 & 10 & 21 & 7 & 9 & 13 & 22 & 48 \\
\hline MUFA & 5 & 7 & 10 & 16 & 36 & 8 & 10 & 15 & 25 & 55 & 4 & 5 & 8 & 13 & 29 & 5 & 7 & 10 & 17 & 37 \\
\hline PUFA & 8 & 11 & 17 & 27 & 59 & 9 & 13 & 19 & 31 & 67 & 6 & 8 & 12 & 19 & 41 & 6 & 9 & 13 & 21 & 46 \\
\hline n-6 PUFA & 9 & 12 & 17 & 29 & 62 & 11 & 15 & 22 & 36 & 78 & 6 & 9 & 13 & 20 & 44 & 7 & 9 & 14 & 22 & 49 \\
\hline n-3 PUFA & 10 & 14 & 20 & 33 & 72 & 12 & 16 & 23 & 38 & 83 & 8 & 12 & 17 & 28 & 60 & 10 & 13 & 19 & 32 & 69 \\
\hline Marine origin $n-3$ PUFA $^{e}$ & 21 & 29 & 42 & 70 & 151 & 18 & 25 & 37 & 60 & 131 & 17 & 24 & 35 & 58 & 126 & 13 & 18 & 26 & 42 & 92 \\
\hline Cholesterol & 8 & 11 & 16 & 25 & 55 & 8 & 12 & 17 & 28 & 61 & 6 & 8 & 12 & 19 & 42 & 6 & 8 & 11 & 18 & 40 \\
\hline
\end{tabular}

Abbreviations: SFA = saturated fatty acids; MUFA = monounsaturated fatty acids; PUFA = polyunsaturated fatty acids.

${ }^{a}$ Number of days of dietary record $=\left[r^{2} /\left(1-r^{2}\right)\right] \times V R$, where $r=$ unobservable correlation coefficient between observed and usual ("true") mean intakes of individuals and VR $=$ within-individual/between-individual variance ratio $\left(\sigma_{\mathrm{w}}{ }^{2} / \sigma_{\mathrm{b}}{ }^{2}\right)$.

bYounger: 30-49 years for women and men; older: 50-69 years for women and 50-76 years for men.

'Sum of $\beta$-carotene, $\alpha$-carotene/2, and cryptoxanthin/2.

dSum of retinol, $\beta$-carotene/12, $\alpha$-carotene/24, and cryptoxanthin/24.

e Sum of eicosapentaenoic acid, docosapentaenoic acid, and docosahexaenoic acid.

consistent with our study, $\mathrm{CV}_{\mathrm{b}}$ was larger in the older than in the younger group. ${ }^{5}$ Additionally, in studies of Japanese adults living in a coastal area (mentioned above), ${ }^{14}$ Korean elderly (mean [SD] age 70.4 [5.8] years using 5- or 6-day 24-h dietary recall), ${ }^{12}$ and Canadian adults (aged 25-44 years using 24-h dietary recall), ${ }^{2,27} \mathrm{CV}_{\mathrm{w}}$ and $\mathrm{CV}_{\mathrm{b}}$ were larger in women than in men. These inconsistent results in some previous studies may be due to differences in study design: these studies ${ }^{2,5,12,27}$ used 24-h dietary recall, whereas we used DR. Cultural factors also likely played a role. ${ }^{2,3}$

The present results have implications for the design and interpretation of dietary assessment. First, among older adults and women, nutrient intake may be more homogeneous from day-to-day and among subjects than for younger adults and men, because smaller $\mathrm{CV}_{\mathrm{w}}$ and $\mathrm{CV}_{\mathrm{b}}$ were observed in older groups and in women than in their respective counterparts. Thus, as compared with men and younger adults, women and older adults may require a smaller group size and fewer days to assess the group's and individual's usual nutrient intake. Second, subjects can be more precisely ranked in groups of younger adults and/or men, because a smaller VR was observed in these groups. A smaller VR means that $\sigma_{\mathrm{w}}{ }^{2}$ is relatively small compared with $\sigma_{\mathrm{b}}{ }^{2}$ and that the difference in intake between individuals can be more easily distinguished. Therefore, if dietary assessment is conducted in individuals or groups by the same methods (number of days and group size) regardless of age or sex, the level of precision of the assessment will differ among the individuals or groups. If an analysis includes estimates of intake with a low level of precision, even in only 1 group, this may decrease the power of the statistical analysis and lead to misinterpretation of the association between dietary factors and an outcome., $2,7,9,12$ Third, regardless of age or sex, a large $\mathrm{CV}_{\mathrm{w}}$ means that many DR days would be required to characterize an individual's usual intake-for example, 4 to 481 days would be needed to achieve within $20 \%$ deviation for younger women. Therefore, 
Table 5. Number of days required to assess mean intake of energy and nutrients with $95 \%$ Cls within the specified $\%$ deviation $\left(D_{1}\right)$ of an individual's mean from usual ("true") mean intake by dietary record according to sex and age group

\begin{tabular}{|c|c|c|c|c|c|c|c|c|c|c|c|c|c|c|c|c|}
\hline \multirow[b]{3}{*}{$\mathrm{D}_{1}$} & \multicolumn{8}{|c|}{ Women $(n=121)$} & \multicolumn{8}{|c|}{ Men $(n=121)$} \\
\hline & \multicolumn{4}{|c|}{ Younger $^{b}(n=58)$} & \multicolumn{4}{|c|}{ Older $^{\mathrm{b}}(n=63)$} & \multicolumn{4}{|c|}{ Younger $^{\mathrm{b}}(n=54)$} & \multicolumn{4}{|c|}{$\operatorname{Older}^{\mathrm{b}}(n=67)$} \\
\hline & $5 \%$ & $10 \%$ & $20 \%$ & $30 \%$ & $5 \%$ & $10 \%$ & $20 \%$ & $30 \%$ & $5 \%$ & $10 \%$ & $20 \%$ & $30 \%$ & $5 \%$ & $10 \%$ & $20 \%$ & $30 \%$ \\
\hline Energy & 65 & 16 & 4 & 2 & 52 & 13 & 3 & 1 & 69 & 17 & 4 & 2 & 53 & 13 & 3 & 1 \\
\hline Protein & 100 & 25 & 6 & 3 & 85 & 21 & 5 & 2 & 99 & 25 & 6 & 3 & 87 & 22 & 5 & 2 \\
\hline Fat & 188 & 47 & 12 & 5 & 187 & 47 & 12 & 5 & 211 & 53 & 13 & 6 & 198 & 49 & 12 & 5 \\
\hline Carbohydrate & 65 & 16 & 4 & 2 & 53 & 13 & 3 & 1 & 67 & 17 & 4 & 2 & 61 & 15 & 4 & 2 \\
\hline Water & 65 & 16 & 4 & 2 & 44 & 11 & 3 & 1 & 84 & 21 & 5 & 2 & 53 & 13 & 3 & 1 \\
\hline Sodium & 174 & 44 & 11 & 5 & 181 & 45 & 11 & 5 & 195 & 49 & 12 & 5 & 178 & 45 & 11 & 5 \\
\hline Potassium & 116 & 29 & 7 & 3 & 110 & 27 & 7 & 3 & 104 & 26 & 6 & 3 & 88 & 22 & 5 & 2 \\
\hline Calcium & 231 & 58 & 14 & 6 & 181 & 45 & 11 & 5 & 246 & 61 & 15 & 7 & 185 & 46 & 12 & 5 \\
\hline Magnesium & 124 & 31 & 8 & 3 & 109 & 27 & 7 & 3 & 112 & 28 & 7 & 3 & 101 & 25 & 6 & 3 \\
\hline Phosphorus & 93 & 23 & 6 & 3 & 77 & 19 & 5 & 2 & 88 & 22 & 6 & 2 & 79 & 20 & 5 & 2 \\
\hline Iron & 190 & 47 & 12 & 5 & 168 & 42 & 11 & 5 & 190 & 47 & 12 & 5 & 150 & 38 & 9 & 4 \\
\hline Zinc & 151 & 38 & 9 & 4 & 121 & 30 & 8 & 3 & 161 & 40 & 10 & 4 & 141 & 35 & 9 & 4 \\
\hline Vitamin $A^{d}$ & 7702 & 1926 & 481 & 214 & 3866 & 966 & 242 & 107 & 7563 & 1891 & 473 & 210 & 6737 & 1684 & 421 & 187 \\
\hline Vitamin D & 1713 & 428 & 107 & 48 & 1535 & 384 & 96 & 43 & 1728 & 432 & 108 & 48 & 1337 & 334 & 84 & 37 \\
\hline$\alpha$-tocopherol & 205 & 51 & 13 & 6 & 210 & 52 & 13 & 6 & 245 & 61 & 15 & 7 & 223 & 56 & 14 & 6 \\
\hline Vitamin K & 726 & 181 & 45 & 20 & 500 & 125 & 31 & 14 & 566 & 142 & 35 & 16 & 610 & 153 & 38 & 17 \\
\hline Vitamin $B_{1}$ & 260 & 65 & 16 & 7 & 179 & 45 & 11 & 5 & 310 & 77 & 19 & 9 & 205 & 51 & 13 & 6 \\
\hline Vitamin $B_{2}$ & 222 & 56 & 14 & 6 & 128 & 32 & 8 & 4 & 203 & 51 & 13 & 6 & 167 & 42 & 10 & 5 \\
\hline Niacin & 228 & 57 & 14 & 6 & 185 & 46 & 12 & 5 & 238 & 60 & 15 & 7 & 204 & 51 & 13 & 6 \\
\hline Vitamin $\mathrm{B}_{6}$ & 172 & 43 & 11 & 5 & 126 & 32 & 8 & 4 & 187 & 47 & 12 & 5 & 138 & 35 & 9 & 4 \\
\hline Vitamin $\mathrm{B}_{12}$ & 1657 & 414 & 104 & 46 & 1205 & 301 & 75 & 33 & 1418 & 355 & 89 & 39 & 1428 & 357 & 89 & 40 \\
\hline Folate & 412 & 103 & 26 & 11 & 234 & 59 & 15 & 7 & 441 & 110 & 28 & 12 & 379 & 95 & 24 & 11 \\
\hline Vitamin C & 415 & 104 & 26 & 12 & 289 & 72 & 18 & 8 & 434 & 108 & 27 & 12 & 390 & 97 & 24 & 11 \\
\hline SFA & 257 & 64 & 16 & 7 & 256 & 64 & 16 & 7 & 312 & 78 & 20 & 9 & 262 & 65 & 16 & 7 \\
\hline MUFA & 255 & 64 & 16 & 7 & 261 & 65 & 16 & 7 & 278 & 69 & 17 & 8 & 276 & 69 & 17 & 8 \\
\hline PUFA & 250 & 62 & 16 & 7 & 247 & 62 & 15 & 7 & 254 & 64 & 16 & 7 & 242 & 61 & 15 & 7 \\
\hline n-6 PUFA & 271 & 68 & 17 & 8 & 288 & 72 & 18 & 8 & 282 & 70 & 18 & 8 & 279 & 70 & 17 & 8 \\
\hline$n-3$ PUFA & 481 & 120 & 30 & 13 & 501 & 125 & 31 & 14 & 499 & 125 & 31 & 14 & 514 & 129 & 32 & 14 \\
\hline Marine origin $n-3$ PUFA ${ }^{e}$ & 2194 & 549 & 137 & 61 & 1666 & 416 & 104 & 46 & 2357 & 589 & 147 & 65 & 1505 & 376 & 94 & 42 \\
\hline Cholesterol & 428 & 107 & 27 & 12 & 404 & 101 & 25 & 11 & 369 & 92 & 23 & 10 & 348 & 87 & 22 & 10 \\
\hline
\end{tabular}

Abbreviations: SFA = saturated fatty acids; MUFA = monounsaturated fatty acids; PUFA = polyunsaturated fatty acids.

${ }^{a}$ Number of days of dietary record $=\left(1.96 \times C V_{w} / D_{1}\right)^{2}$, where $D_{1}=$ the specified \% deviation of individual mean from usual ("true") mean intake.

bYounger: 30-49 years for women and men; older: 50-69 years for women and 50-76 years for men.

'Sum of $\beta$-carotene, $\alpha$-carotene/2, and cryptoxanthin/2.

dSum of retinol, $\beta$-carotene/12, $\alpha$-carotene/24, and cryptoxanthin/24.

eSum of eicosapentaenoic acid, docosapentaenoic acid, and docosahexaenoic acid.

use of an alternative method (eg, a semi-quantitative food frequency questionnaire) that can estimate usual intakes over a longer period than DR or dietary recall may be necessary to accord with the study objective, study design, demographic characteristics of the population, and available resources. $^{3,6,12,15}$

Several limitations of this study warrant mention. First, the generalizability of our results is hampered by the fact that the present subjects were not randomly sampled from the general Japanese population but were instead volunteers and possibly health-conscious. As we lacked information on the subjects' characteristics, including education and occupation, we could not determine how such characteristics influenced our findings. Mennen et $\mathrm{al}^{13}$ assumed that the dietary recall of subjects who completed a protocol is more precise (smaller $\mathrm{CV}_{\mathrm{w}}$ ) than that of subjects who dropped out. Hebert et $\mathrm{al}^{11}$ suggested that $\mathrm{CV}_{\mathrm{b}}$ is smaller in a population with higher socioeconomic status (SES). Thus, because of precise recording, $\mathrm{CV}_{\mathrm{w}}$ might have been smaller in our volunteers than in the general population consuming a similar diet. $\mathrm{CV}_{\mathrm{b}}$ might have been smaller because of limited variation in some variables (eg, health-consciousness). If so, the group size required to estimate a group's mean intake in the general population would be larger than the estimates observed here (Table 3). Additionally, the number of days required to precisely estimate an individual's usual intake in the general population would be larger than the estimates observed here (Table 5). Conversely, as we did not know whether VR was lower or higher in our volunteers than in the general population, the number of days required to rank individuals based on their intakes within the general population is unclear, that is, we cannot conclude that the required number of days is larger or smaller than the estimates observed here (Table 4).

Second, the subjects were married men and women living together, who likely frequently have the same meals. This implies that the $\mathrm{CV}_{\mathrm{w}}$ and $\mathrm{CV}_{\mathrm{b}}$ of men in this study might be underestimated as compared with the general male population because the daily menu is probably usually decided by 
women, who in our study had a smaller $\mathrm{CV}_{\mathrm{w}}$ and $\mathrm{CV}_{\mathrm{b}}$. Third, although we compared within- and between-individual variation between sexes and age groups (younger vs older), several unanticipated confounding factors, such as SES, might be present in our analysis. If the distribution of SES differs between sexes or age groups, and SES has an effect on dietary habits, it should be adjusted for in the analysis. However, we designed the study so as to consider important confounding factors that may affect the comparisons. For example, sex itself is an important confounding factor in a comparison between age groups, and age is the same in a comparison between sexes. To address this problem, we recruited the same number of subjects for each sex and age category. Living area, season, and timing of data collection (weekday or weekend day) are other possible confounding factors, and they were equalized between sexes and age groups. ${ }^{1-4,28,29}$ Finally, DR is susceptible to measurement error due to erroneous recording and potential changes in eating behavior. ${ }^{3}$ However, the adequacy of reported energy intake was likely adequate at the group level, given that the mean value of EI/EER was around 1.0 .

In conclusion, the present study of Japanese adults showed that $\mathrm{CV}_{\mathrm{w}}$ and $\mathrm{CV}_{\mathrm{b}}$ were larger in a younger group than in an older group and larger in men than in women for energy and most nutrients. Precise estimation of usual nutrient intakes requires consideration of differences not only in $\mathrm{CV}_{\mathrm{w}}$ and $\mathrm{CV}_{\mathrm{b}}$ by age and sex, but also in group size and number of days estimated using $\mathrm{CV}_{\mathrm{w}}$ and $\mathrm{CV}_{\mathrm{b}}$. The present findings may have important implications for the design and interpretation of dietary assessment in Japanese adults.

\section{ONLINE ONLY MATERIAL}

Abstract in Japanese.

\section{ACKNOWLEDGMENTS}

This work was supported by grants from the Japanese Ministry of Health, Labour and Welfare. All the authors contributed to the preparation of the manuscript and approved the final version submitted for publication. A.F. performed statistical analyses and wrote the manuscript. K.A. and K.M. assisted in writing and editing the manuscript. S.S. contributed to the concept and design of the study, study protocol, and data collection, and assisted in writing and editing the manuscript. H.O., N.H., A.N., H.T., A.M., M.F., and C.D. were involved in the study design, data collection, and data management.

Conflicts of interest: None declared.

\section{REFERENCES}

1. Gibson RS. Principles of nutritional assessment. 2nd ed. New York: Oxford University Press; 2005.
2. Beaton GH, Milner J, Corey P, McGuire V, Cousins M, Stewart E, et al. Sources of variance in 24-hour dietary recall data: implications for nutrition study design and interpretation. Am J Clin Nutr. 1979;32:2546-59.

3. Willett WC. Nutritional epidemiology. 2nd ed. New York: Oxford University Press; 1998.

4. Tokudome Y, Imaeda N, Nagaya T, Ikeda M, Fujiwara N, Sato J, et al. Daily, weekly, seasonal, within- and between-individual variation in nutrient intake according to four season consecutive 7 day weighed diet records in Japanese female dietitians. J Epidemiol. 2002;12:85-92.

5. Cai H, Shu XO, Hebert JR, Jin F, Yang G, Liu DK, et al. Variation in nutrient intakes among women in Shanghai, China. Eur J Clin Nutr. 2004;58:1604-11.

6. Ribas-Barba L, Serra-Majem L, Román-Viñas B, Ngo J, GarcíaAlvarez A. Effects of dietary assessment methods on assessing risk of nutrient intake adequacy at the population level: from theory to practice. Br J Nutr. 2009;101 Suppl 2:S64-72.

7. Nelson M, Black AE, Morris JA, Cole TJ. Between- and withinsubject variation in nutrient intake from infancy to old age: estimating the number of days required to rank dietary intakes with desired precision. Am J Clin Nutr. 1989;50:155-67.

8. Neuhaus JM, Murphy SP, Davis MA. Age and sex differences in variation of nutrient intakes among U.S. adults. Epidemiology. 1991;2:447-50.

9. Pereira RA, Araujo MC, Lopes Tde S, Yokoo EM. How many 24-hour recalls or food records are required to estimate usual energy and nutrient intake? Cad Saude Publica. 2010;26: 2101-11.

10. Cai H, Yang G, Xiang YB, Hebert JR, Liu DK, Zheng W, et al. Sources of variation in nutrient intakes among men in Shanghai, China. Public Health Nutr. 2005;8:1293-9.

11. Hebert JR, Gupta PC, Mehta H, Ebbeling CB, Bhonsle RR, Varghese F. Sources of variability in dietary intake in two distinct regions of rural India: implications for nutrition study design and interpretation. Eur J Clin Nutr. 2000;54:479-86.

12. Oh SY, Hong MH. Within- and between-person variation of nutrient intakes of older people in Korea. Eur J Clin Nutr. 1999;53:625-9.

13. Mennen LI, Bertrais S, Galan P, Arnault N, Potier de Couray G, Hercberg S. The use of computerised $24 \mathrm{~h}$ dietary recalls in the French SU.VI.MAX Study: number of recalls required. Eur J Clin Nutr. 2002;56:659-65.

14. Egami I, Wakai K, Kaitoh K, Kawamura T, Tamakoshi A, Lin Y, et al. Intra- and inter-individual variations in diets of the middleaged and the elderly. Nihon Koshu Eisei Zasshi. 1999;46: 828-37 (in Japanese).

15. Ogawa K, Tsubono Y, Nishino Y, Watanabe Y, Ohkubo T, Watanabe $\mathrm{T}$, et al. Inter- and intra-individual variation of food and nutrient consumption in a rural Japanese population. Eur J Clin Nutr. 1999;53:781-5.

16. Ministry of Public Management, Home Affairs, Posts and Telecommunications. Japan National Census, 2000: Statistical tables according to prefectures, cities, city blocks, and villages, 2000 (in Japanese).

17. Murakami K, Sasaki S, Takahashi Y, Okubo H, Hirota N, Notsu A, et al. Reproducibility and relative validity of dietary glycaemic index and load assessed with a self-administered 
diet-history questionnaire in Japanese adults. $\mathrm{Br} \mathrm{J}$ Nutr. 2008;99:639-48.

18. Okubo H, Murakami K, Sasaki S, Kim MK, Hirota N, Notsu A, et al. Relative validity of dietary patterns derived from a selfadministered diet history questionnaire using factor analysis among Japanese adults. Public Health Nutr. 2010;13:1080-9.

19. Yamada M, Sasaki S, Murakami K, Takahashi Y, Okubo H, Hirota N, et al. Estimation of trans fatty acid intake in Japanese adults using 16-day diet records based on a food composition database developed for the Japanese population. J Epidemiol. 2010;20:119-27.

20. Kobayashi S, Honda S, Murakami K, Sasaki S, Okubo H, Hirota $\mathrm{N}$, et al. Both comprehensive and brief self-administered diet history questionnaires satisfactorily rank nutrient intakes in Japanese adults. J Epidemiol. 2012;22:151-9.

21. Science and Technology Agency. Standard tables of food composition in Japan, 2010. Tokyo: Ministry of Education, Culture, Sports, Science and Technology; 2010 (in Japanese).

22. Ganpule AA, Tanaka S, Ishikawa-Takata K, Tabata I. Interindividual variability in sleeping metabolic rate in Japanese subjects. Eur J Clin Nutr. 2007;61:1256-61.

23. Ministry of Health, Labour and Welfare of Japan. Dietary reference intakes for Japanese, 2010. Tokyo: Daiichi Shuppan
Publishing Co., Ltd.; 2009 (in Japanese).

24. Jahns L, Carriquiry A, Arab L, Mroz TA, Popkin BM. Withinand between-person variation in nutrient intakes of Russian and U.S. children differs by sex and age. J Nutr. 2004;134:3114-20.

25. Manning WG. The logged dependent variable, heteroscedasticity, and the retransformation problem. J Health Econ. 1998; 17:283-95.

26. Hunt WC, Leonard AG, Garry PJ, Goodwin JS. Components of variance in dietary data for an elderly population. Nutr Res. 1983;3:433-44.

27. Beaton GH, Milner J, McGuire V, Feather TE, Little JA. Source of variance in 24-hour dietary recall data: implications for nutrition study design and interpretation. Carbohydrate sources, vitamins, and minerals. Am J Clin Nutr. 1983;37:986-95.

28. Owaki A, Takatsuka N, Kawakami N, Shimizu H. Seasonal variations of nutrient intake assessed by 24 hour recall method. Jpn J Nutr Diet. 1996;54:11-8 (in Japanese).

29. Sasaki S, Takahashi T, Iitoi Y, Iwase Y, Kobayashi M, Ishihara $\mathrm{J}$, et al. Food and nutrient intakes assessed with dietary records for the validation study of a self-administered food frequency questionnaire in JPHC Study Cohort I. J Epidemiol. 2003; 13(1 Suppl):S23-50. 